\title{
Luminescence spectroscopy of ${ }^{3} P_{1}$ and ${ }^{3} P_{0}$ state atomic mercury isolated in solid $\mathrm{Ar}$, $\mathrm{Kr}$, and $\mathrm{Xe}$
}

\author{
Martin A. Collier and John G. McCaffrey \\ Department of Chemistry, National University of Ireland, Maynooth, Co. Kildare, Ireland
}

(Received 23 April 2003; accepted 10 September 2003)

\begin{abstract}
Multicomponent emission bands are recorded for the ${ }^{3} P_{1} \rightarrow{ }^{1} S_{0}$ transition of atomic mercury isolated at single sites in solid $\mathrm{Ar}, \mathrm{Kr}$, and $\mathrm{Xe}$ matrices. A blueshift observed at elevated temperatures on the $273 \mathrm{~nm}$ emission of $\mathrm{Hg} / \mathrm{Xe}$ is identified in line shape analysis as arising from decreasing intensity of the central component in the band profile. The origin of the multiple components in the emission bands is ascribed to the existence of several vibronic modes which lead to excited state stabilization in the $\mathrm{Hg}\left({ }^{3} P_{1}\right) / R G$ matrix systems. A detailed description of these modes and their energetics is presented in the paper directly following. Photoexcitation of the ${ }^{3} P_{1}$ state also yields small amounts of ${ }^{3} P_{0}$ state emission. $\mathrm{Hg}$ atom ${ }^{3} P_{1}$ to ${ }^{3} P_{0}$ state intramultiplet relaxation (IMR) is most efficient in $\mathrm{Hg} / \mathrm{Xe}$ where the ratio of this relaxation channel to ${ }^{3} P_{1}$ state radiative decay is $1 / 200$ as established in time-integrated emission spectra. Despite the weakness of IMR, pulsed laser excitation combined with photon counting detection provide time-gated ${ }^{3} P_{0}$ state emission spectra largely free of the more intense ${ }^{3} P_{1}$ state emission. Such emission spectra recorded under high resolution for the ${ }^{3} P_{0} \rightarrow{ }^{1} S_{0}$ transition of atomic mercury isolated in solid Xe provide the first example of the occurrence of a zero-phonon lines for a metal atom isolated in a rare gas matrix. $W p$ line shape analysis conducted on the emission bands recorded at specific temperatures, confirm this assignment. The electron-phonon coupling strength (Huang-Rhys, $S$ factor) extracted in the line shape fits for the $\mathrm{Hg} / \mathrm{Xe}$ transition is 1.3. Slightly stronger coupling is identified in $\mathrm{Kr}$ ( $S$ $=2.2$ ) and stronger still in $\operatorname{Ar}(S=3.3)$. Analysis of the diatomic $\mathrm{Hg} \cdot \mathrm{RG}$ potential energy curves reveal that the origin of the weak electron-phonon coupling lies primarily in the similarity in the ground and excited states, but also indicates the site size offered by the host solid plays a role. (C) 2003 American Institute of Physics. [DOI: 10.1063/1.1623173]
\end{abstract}

\section{INTRODUCTION}

The metal atom whose spectroscopy has been most extensively studied, both in 1:1 van der Waals (Hg.RG) complexes $^{1}$ and isolated in solid rare gas matrices ${ }^{2}(\mathrm{Hg} / \mathrm{RG})$, is mercury. This is particularly true of the $6 p^{3} P_{1} \leftrightarrow 6 s^{1} S_{0}$ transition which was one of the first atomic systems ${ }^{3}$ studied with the matrix-isolation technique. Despite the existence, for more than a decade now, of accurate $\mathrm{Hg}$. RG pair potentials, obtained from spectroscopy of the diatomic $\mathrm{Hg} \cdot \mathrm{RG}$ complexes stabilized in supersonic expansions, no calculations have appeared in the literature of the corresponding matrix absorption or emission spectra. With the availability of accurate interaction potentials for the $\mathrm{Hg}$. RG diatomics, we embarked upon spectral simulations of the matrix absorption and emission spectroscopies using the pair-potentials approach our group has implemented in the Zn (Ref. 4) and Cd (Ref. 5) matrix systems. However, with several emission pathways identified in the theoretical work, it was necessary to extend experimental analysis of the emission spectroscopy to provide sufficient information for comparison with predictions. Specifically, the temperature dependence of the matrix emission is examined, line shape analysis is performed, and excitation spectra are recorded. Details of the pair-potentials simulations and a comparison with the experimental data are presented in the paper ${ }^{6}$ directly following.

The spectroscopy and reactivity of atomic mercury iso- lated in low temperature solids has been studied in greatest depth and scope by the Orsay group of Crepin and Tramer ${ }^{7}$ (CT). As their work has been recently reviewed, ${ }^{8}$ only aspects relating to the spectroscopy of the $6 p^{3} P_{1}$ and $6 p{ }^{3} P_{0}$ states will be addressed here. Absorption recorded by CT with a deuterium lamp yielded spectra in agreement with the earlier absorption work ${ }^{9}$ showing a threefold split band for $\mathrm{Hg} / \mathrm{Xe}$ in the vicinity of the gas phase $6 p{ }^{3} P_{1} \leftrightarrow 6 s{ }^{1} S_{0}$ transition of atomic mercury at $253.6 \mathrm{~nm}$. Featureless bands, progressively blueshifted from the gas phase transition, were observed in $\mathrm{Kr}$ and Ar matrices. Dye laser excitation of the $6 p{ }^{3} P_{1}$ state absorption produced multiple emission bands in the UV in all three rare gas matrices. Although excitation spectra were not presented in CT's work, ${ }^{7}$ the most intense emission bands had the smallest Stokes' shifts and were tentatively assigned to occupancy of atomic mercury in substitutional sites. $\mathrm{Hg} / \mathrm{Xe}$ emission was quite different to that recorded for $\mathrm{Hg} / \mathrm{Kr}$ and $\mathrm{Hg} / \mathrm{Ar}$ in that the Stokes' shift was very large and the emission bandwidth was much greater than the absorption bandwidth.

CT also identified narrow "atomic-like" features in the matrix emission spectra which they assigned to the forbidden $6 p^{3} P_{0} \rightarrow 6 s{ }^{1} S_{0}$ transition. The linewidth of these transitions decreased in the order Ar to Xe but the shift of the band positions was irregular with the emission in Ar located between that in $\mathrm{Kr}$ and $\mathrm{Xe}$. Other work by $\mathrm{CT}$ on matrix- 
isolated atomic $\mathrm{Hg}$ has involved an examination of the relaxation of the excited atomic $6 p{ }^{1} P_{1}$ state following resonance excitation with synchrotron radiation ${ }^{10,11}$ and pulsed laser excitation. ${ }^{12,13}$ Population of all three triplet spin-orbit states $\left({ }^{3} P_{2,1,0}\right)$ was observed as a result of ${ }^{1} P_{1}$ excitation. More recently, Chergui and co-workers ${ }^{14}$ have conducted spectroscopic studies in neon matrices.

This report presents a study of the temperature dependence of the ${ }^{3} P_{1} \rightarrow{ }^{1} S_{0}$ and ${ }^{3} P_{0} \rightarrow{ }^{1} S_{0}$ transitions of atomic mercury isolated in the solid rare gases $\mathrm{Ar}, \mathrm{Kr}$, and $\mathrm{Xe}$, resulting from resonance excitation of the ${ }^{3} P_{1}$ excited state. This state is accessed with continuous lamp and pulsed laser excitation facilitating a clear distinction of the latter forbidden transition and the former, nearly fully allowed transition. Excitation spectra are presented for the first time allowing identification of the origin of multiple emission features. Line shape analysis of high resolution ${ }^{3} P_{0} \rightarrow{ }^{1} S_{0}$ emission scans allow the strength of the electron-phonon coupling to be determined.

\section{EXPERIMENT}

Solid Hg/RG ( $R G=A r, K r$, and Xe) samples were prepared by co-condensing $\mathrm{Hg}$ vapor with the rare gas of interest onto a $\mathrm{CaF}_{2}$ window at temperatures of 22, 28, and $35 \mathrm{~K}$ for $\mathrm{Ar}, \mathrm{Kr}$, and Xe, respectively. A minimum temperature of $12 \mathrm{~K}$, achieved with an APD Cryogenics closed-cycle helium displex system (Model HC-2), was, unless otherwise stated, used for the spectral scans reported. Temperature was monitored with a Scientific Instruments 9600-1 silicon diode mounted on the copper holder of the $\mathrm{CaF}_{2}$ window. High deposition temperatures were selected to produce samples as free as possible of multiple trapping sites.

The deposition method used, exploits the high vapor pressure of mercury whereby metal pick-up by the rare gases Ar (BOC Gases, Research Grade C), Kr and Xe (Linde Gas, 99.998\%) flowing over an Hg reservoir at room temperature (296 K), entrains sufficient Hg vapor to produce moderately absorbing samples $(\mathrm{OD}=0.9)$. The reservoir consisted of a $15 \mathrm{~cm}$ long stainless steel tube, $1.5 \mathrm{~cm}$ in diameter containing $1 \mathrm{~cm}^{3}$ of mercury, connected by $0.25 \mathrm{in}$. tubing to the gas inlet of the matrix shroud. Pick-up is controlled by a threeway valve arrangement where two valves isolate the reservoir from the matrix rig, except during $\mathrm{Hg} / \mathrm{RG}$ sample formation, when they are opened and a third valve, directly connecting the GHS to the matrix, is closed. Freeze-pumpthaw cycles were used to remove air from the reservoir after the initial fill. Vacuum, typically in the low $10^{-7}$ mbar range, was maintained in the sample chamber at room temperature using an oil diffusion pump backed by an Edwards 3 Rotary Pump. The vacuum was monitored using an Alcatel CF2P cold cathode gauge. Following cool down the vacuum dropped to approximately $9 \times 10^{-8}$ mbar at $12 \mathrm{~K}$ prior to sample deposition.

The rare gases were handled using a dedicated gas handling system (GHS), maintained at vacuum in the low $10^{-8} \mathrm{mBar}$ range by a Pfeiffer Balzers turbo-molecular (TPU-180H) pump. An ionization gauge, combined with a Granville-Philips (GP) vacuum gauge controller (model 307), was used to monitor the vacuum in the GHS. The amounts of rare gas in the gas handling system before and after sample deposition was monitored by two baratron gauges (Tylan General CDLD-11 and 31) sensitive in the ranges $0-10$ and $0-1000$ Torr, respectively. This allowed the rate of gas deposition to be determined. The RG was admitted to the sample chamber via a Granville-Philips variable leak valve (Type 203). The samples reported here were deposited at a rate of $8-10 \mathrm{mmol} / \mathrm{h}$ for a period of 30 minutes.

The spectroscopic measurements reported were achieved using three optical arrangements, which can be considered in two classes depending on the excitation source employed. (A) Continuous Lamp Excitation yielding steady-state emission spectra and (B) Pulsed Laser Excitation allowing spectral and temporal measurements of the emission to be made.

(A) A continuous, deuterium lamp (Hamamatsu L6310 and a Cathodeon C713 power supply) was used as the light source to record both absorption and excitation spectra. An Acton Research Corporation (ARC) 0.30 m SpectraPro-300i monochromator fitted with a 1200 grooves $/ \mathrm{mm}$ diffraction grating, blazed at $300 \mathrm{~nm}$ was used for wavelength selection. The monochromatic light transmitted through the thin film $\mathrm{Hg} / \mathrm{RG}$ matrix samples, located on a vertical $\mathrm{CaF}_{2}$ window, was focused onto a photomultiplier tube (Hamamatsu, 1P28), by means of a quartz focusing lens (focal length 1 in.) mounted with the PMT on the sample chamber. Absorption spectra of the Hg/RG samples were obtained in the usual manner by rationing sample transmittance spectra with their corresponding blanks, i.e., pure RG films.

Emission was monitored perpendicular to the excitation axis by focussing emitted light onto the entrance slits of an ARC $0.5 \mathrm{~m}$ SpectraPro-500i monochromator fitted with a $1200 \mathrm{~g} / \mathrm{mm}$ grating, blazed at $300 \mathrm{~nm}$. Photon detection was achieved using a Hamamatsu R928-P PMT maintained at $-20^{\circ} \mathrm{C}$ in a Products for Research cooled-housing (Photocool S600). This PMT was operated in photon counting mode by relaying its signal via an amplifier/ discriminator module (Electron Tubes Ltd, type AD6) to the ARC NCL data acquisition and controller unit.

Emission spectra were also recorded with pulsed excitation using a Nd:YAG (Quantel YG 980E-10) laser operating at a repetition rate of $10 \mathrm{~Hz}$. A dye laser (Quantel TDL-90), pumped by the second harmonic of the YAG, was used to produce tuneable laser radiation. The excitation wavelengths required for mercury atom excitation were achieved by mixing the residual YAG fundamental (1064 nm) with the doubled output of the dye laser using DCM as the dye material. KDP crystals, Quantel DCC2 and MCC2, were used to frequency double and mix, respectively, while quartz crystals, Quantel QCC1 and QCC2, were used to compensate for the walk of the resultant beams. Wavelength separation of the mixed beam was achieved with a Pellin-Brocca prism, the deep-UV output of which was trained onto the matrix sample (on a $\mathrm{CaF}_{2}$ window) without focusing optics. Typical laser fluence of $20 \mu \mathrm{J} / \mathrm{mm}^{2}$, measured with a Molectron power-max 500A meter and PM10V1 head, was achieved in the $250 \mathrm{~nm}$ spectral region using only the oscillator and preamplifier stages of the TDL-90 dye laser. The linewidth of the dye laser is $0.8 \mathrm{~cm}^{-1}$ at $560 \mathrm{~nm}$. Emission was monitored perpendicular to the laser beam and recorded in the 


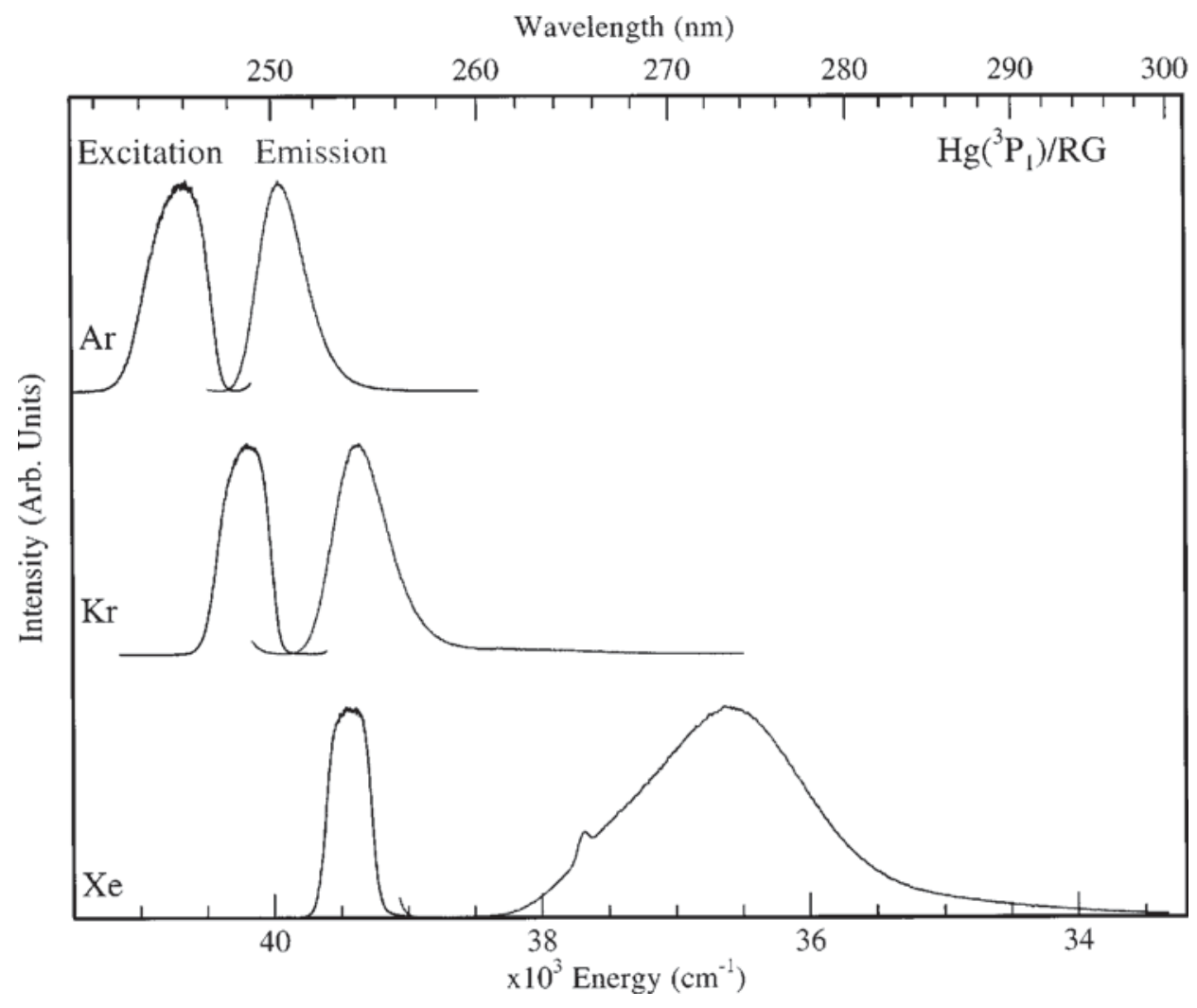

FIG. 1. Emission spectra recorded at $12 \mathrm{~K}$ for the $\mathrm{Hg} / \mathrm{RG}$ systems with lamp excitation of the $\mathrm{Hg}{ }^{3} P_{1} \leftarrow{ }^{1} S_{0}$ transition. The excitation spectra, recorded by monitoring emission at 250.4, 254.1, and $273.9 \mathrm{~nm}$ in $\mathrm{Ar}$, Kr, and Xe, respectively, are shown on the left-hand side of the figure. $\mathrm{Hg} / \mathrm{Ar}, \mathrm{Hg} /$ $\mathrm{Kr}$, and $\mathrm{Hg} / \mathrm{Xe}$ samples were deposited at 22,25 , and $35 \mathrm{~K}$, respectively. photon counting manner described previously for the steadystate measurements, except that each data point in the spectrum was obtained by averaging ten laser shots.

(B) Emission decay measurements were conducted with photon counting detection of the emission produced with pulsed (6 ns) laser excitation and recorded with a multistop, multichannel scaler (MCS). The signal from the photon counting (R928-P) emission PMT was amplified by an Ortec (Model VT120) fast-timing preamplifier and relayed to an Ortec (Model 584) constant-fraction discriminator (CFD) to limit electronic noise. The fast NIM output of the CFD was passed simultaneously to an Ortec (Model 661) ratemeter and to the stop-in on a $2 \mathrm{GHz}$ multichannel scaler (Fast ComTec, Model 7886) which has a minimum dwell time of 0.5 ns per channel. The start pulse for the MCS unit was obtained from the $Q$-switch prepulse of the YG 980 laser. The temporal resolution of this arrangement has been determined to be approximately 500 ns limited largely by the poor pulse-pair resolution of the R928-P PMT when high intensity, low repetition laser excitation is used. This characteristic allows the recording of only long-lived emission decay $(t \geqslant 1 \mu \mathrm{s})$ in the pulsed laser/MCS detection arrangement. Decay times were obtained from the emission decay curves by fitting single or multiple exponential functions to the decay curves. Gaussian curve fits of the emission bands were performed with Galactic’s Grams/32 software.

\section{RESULTS}

\section{A. $\mathrm{Hg}^{3} P_{1} \leftrightarrow{ }^{1} S_{0}$ emission and excitation spectra}

Time-integrated emission spectra produced with continuous lamp excitation of the $\mathrm{Hg}^{3} P_{1}$ state are presented in Fig.
1 for Ar, Kr, and Xe samples. The overall features of the $\mathrm{Hg} / \mathrm{RG}$ spectra agree well with the nanosecond time-resolved spectra presented previously ${ }^{7}$ by Crepin and Tramer. One difference is the presence of a weak, resolved feature at $265.1 \mathrm{~nm}$ in $\mathrm{Hg} / \mathrm{Xe}$ that is due to the long-lived ${ }^{3} P_{0}$ state emission of $\mathrm{Hg}$. The main emission features are centered at 250.3, 254.1, and $273.0 \mathrm{~nm}$ in $\mathrm{Ar}, \mathrm{Kr}$, and Xe, respectively as listed in Table I. Excitation spectra recorded for these emission wavelengths are shown on the left-hand side of Fig. 1 and correspond to the dominant features in the previously reported $^{7,9}$ absorption spectra. As observed by CT, the emission band in $\mathrm{Hg} / \mathrm{Xe}$, centered at $273 \mathrm{~nm}$, has a large bandwidth and Stokes' shift compared with those in the $\mathrm{Hg} / \mathrm{Ar}$ and $\mathrm{Hg} / \mathrm{Kr}$ systems. Moreover, the $\mathrm{Hg} / \mathrm{Xe}$ emission band exhibits a clear asymmetry. To investigate the origin of this asymmetry we have examined the temperature dependence of the $\mathrm{Hg} / \mathrm{Xe}$ emission and conducted line shape analyses at $12 \mathrm{~K}$ and elevated temperatures.

TABLE I. Photophysical characteristics of the triplet $6 p{ }^{3} P_{1} \leftrightarrow 6 s{ }^{1} S_{0}$ transition of matrix-isolated atomic mercury. $\lambda_{E x}$ indicates the position of the central component of the threefold split excitation spectrum and $\lambda_{E m}$ indicates the emission band center in nm units. The full-width at half-maximum intensity of the excitation/emission features is denoted by $\Delta$ and the Stokes shift by SS-both in wave number $\left(\mathrm{cm}^{-1}\right)$ units.

\begin{tabular}{ccccccc}
\hline \hline \multirow{2}{*}{$\begin{array}{c}\text { Hg/RG } \\
\text { system }\end{array}$} & \multicolumn{2}{c}{ Excitation } & & \multicolumn{2}{c}{ Emission } & \\
\cline { 2 - 3 } \cline { 5 - 6 } & $\lambda_{E x}(\mathrm{~nm})$ & $\Delta\left(\mathrm{cm}^{-1}\right)$ & & $\lambda_{E m}(\mathrm{~nm})$ & $\Delta\left(\mathrm{cm}^{-1}\right)$ & \multirow{2}{*}{$\mathrm{SS}\left(\mathrm{cm}^{-1}\right)$} \\
\hline $\mathrm{Ar}$ & 245.9 & 484 & & 250.3 & 399 & 715 \\
$\mathrm{Kr}$ & 248.9 & 397 & & 254.1 & 465 & 816 \\
$\mathrm{Xe}$ & 253.6 & 344 & & 273.0 & 1472 & 2802 \\
\hline \hline
\end{tabular}




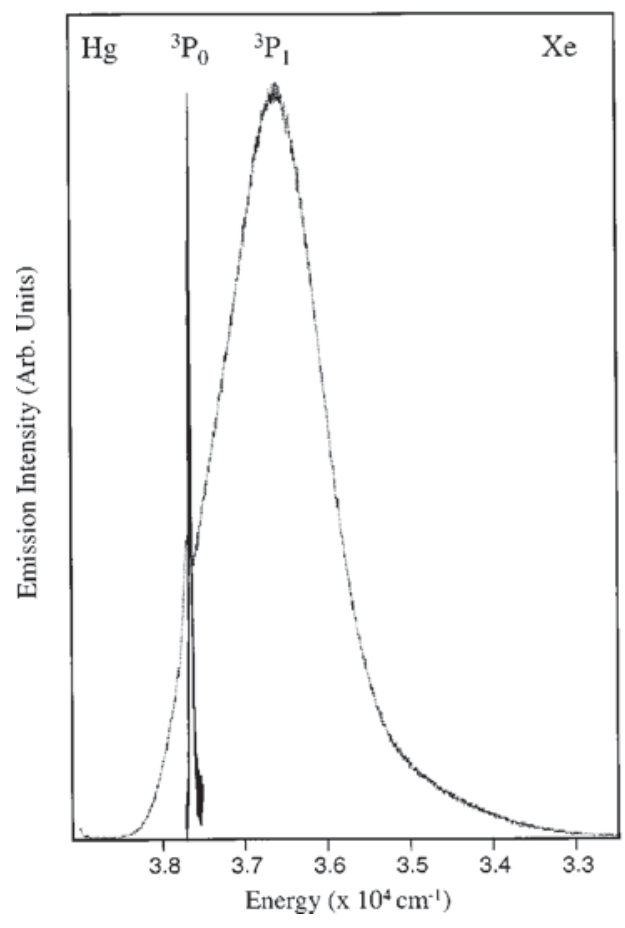

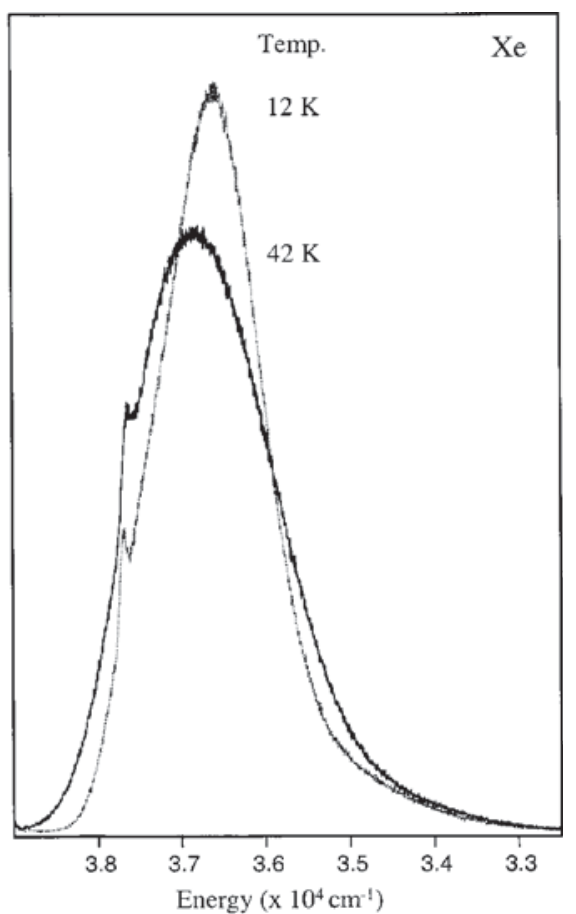

FIG. 2. Details of $\mathrm{Hg} / \mathrm{Xe}$ emission. The panel on the right shows a comparison of emission spectra recorded at 12 and $42 \mathrm{~K}$. In this comparison a reversible blueshift in the band maximum occurs with increasing temperature. The panel on the left shows a comparison of the emission spectra produced with pulsed and continuous excitation. The narrow feature at 265.1 nm was recorded with pulsed laser excitation and is gated to show only long-lived ${ }^{3} P_{0}$ emission. The comparison indicates the weak, sharp feature in the time integrated emission, produced with continuous lamp excitation, is due to the presence of the ${ }^{3} P_{0}$ emission on a broad ${ }^{3} P_{1}$ emission band centered at $273 \mathrm{~nm}$.
The right-hand panel of Fig. 2 provides a comparison of the $\mathrm{Hg} / \mathrm{Xe}$ emission recorded at 12 and $42 \mathrm{~K}$. As expected the emission bandwidth increases at elevated temperature but contrary to expectation, the band center blueshifts. This effect is completely reversible because, although not shown in Fig. 2, the $12 \mathrm{~K}$ scan recorded after sample warming to $42 \mathrm{~K}$ is identical to the previous $12 \mathrm{~K}$ scan. Line shape analysis of the time-integrated $\mathrm{Hg} / \mathrm{Xe}$ emission spectrum is complicated by the presence of a small amount of ${ }^{3} P_{0}$ state emission in addition to ${ }^{3} P_{1}$ emission. The location of the former emission is revealed by overlaying, as shown on the left-hand side of Fig. 2, the ${ }^{3} P_{0}$ emission spectrum produced with pulsed laser excitation. As indicated in this comparison, the emission bands of these two states are quite different- the ${ }^{3} P_{0}$ state is very narrow while the ${ }^{3} P_{1}$ state is broad.

In the line shape analysis conducted on the $\mathrm{Hg} / \mathrm{Xe}$ emission, provision was made in the fits for the presence of the narrow ${ }^{3} P_{0}$ state emission band. A satisfactory fit of the $12 \mathrm{~K}$ emission band, shown on the bottom left-hand side of Fig. 3, is obtained with three Gaussian functions (not counting the narrow ${ }^{3} P_{0}$ state emission). Details of the $12 \mathrm{~K}$ fits are presented in Table II which gives the positions of the ${ }^{3} P_{1}$ emis-
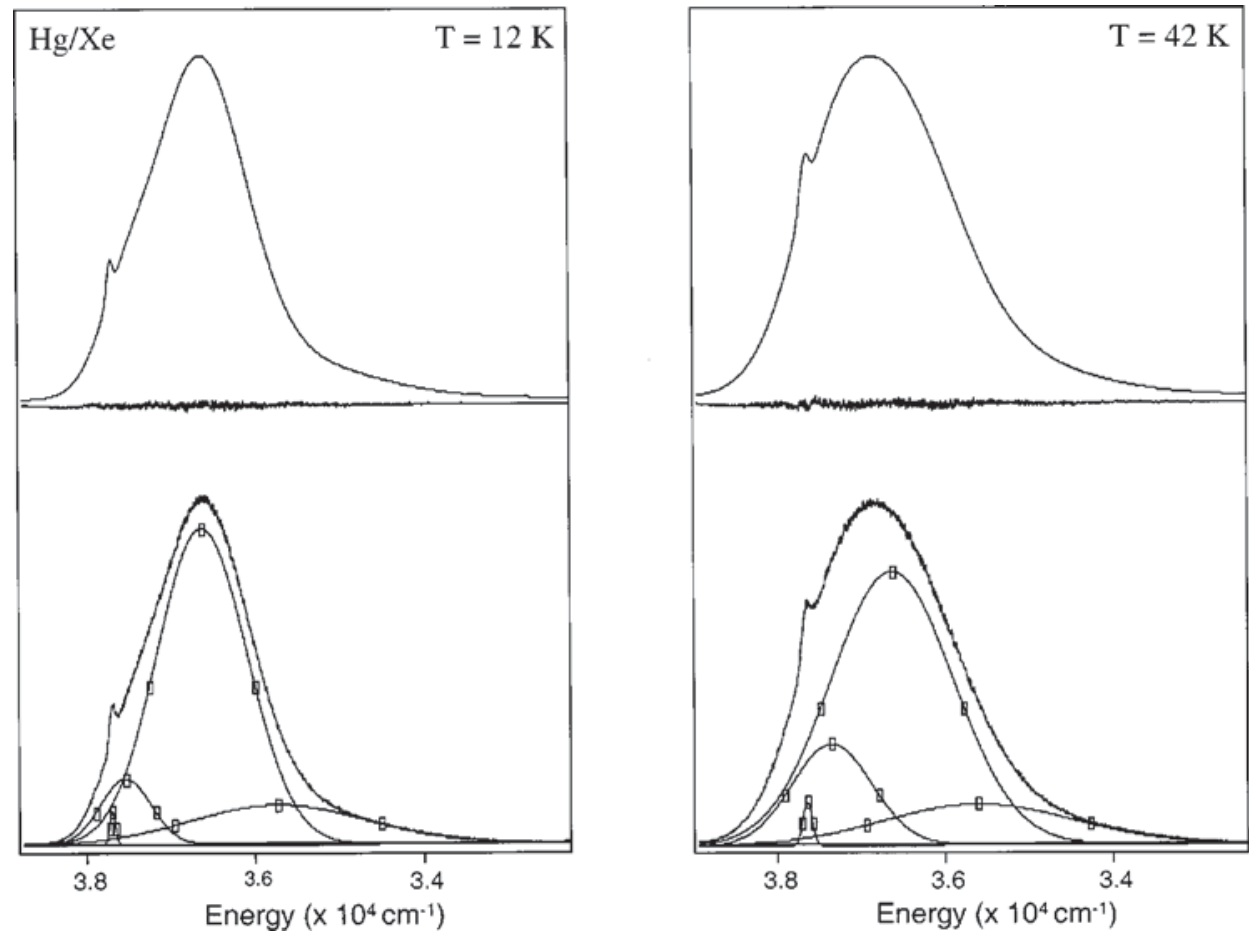

FIG. 3. Line shape analysis of ${ }^{3} P_{1}$ emission in the $\mathrm{Hg} / \mathrm{Xe}$ system. The panel on the left shows an acceptable fit of the spectra recorded at $12 \mathrm{~K}$. In this fit, three broad Gaussian functions are required in addition to one, narrow function included for the ${ }^{3} P_{0}$ state emission. The quality of the fit is indicated in the panel above which shows the residuals (noisy horizontal line) existing between the fit and the data, while the solid curve shows the emission line shape generated by the fit. The panel on the right shows a fit of the high temperature emission. As in the $12 \mathrm{~K}$ fits, three broad+1 narrow Gaussian functions provide an adequate fit. 
TABLE II. Parameters extracted in Gaussian fits of the Hg/RG 12 K emission spectra produced with continuous lamp excitation. The Hg/Xe spectra are shown in the bottom left-hand side of Fig. 3 while the fits for $\mathrm{Hg} / \mathrm{Kr}$ and $\mathrm{Hg} / \mathrm{Ar}$ are shown in Fig. 4. The band areas were determined by numerical integration of the fitted curves.

\begin{tabular}{ccccc}
\hline \hline Hg/RG & $\begin{array}{c}\text { Band center } \\
\nu_{0}\left(\mathrm{~cm}^{-1}\right)\end{array}$ & $\begin{array}{c}\text { Band height } \\
\text { (counts) }\end{array}$ & $\begin{array}{c}\text { Band width } \\
\Delta\left(\mathrm{cm}^{-1}\right)\end{array}$ & $\begin{array}{c}\text { Integrated } \\
\text { area (counts) }\end{array}$ \\
\hline \multirow{3}{*}{$\mathrm{Xe}$} & 37693.9 & 1658 & 84.3 & $1.488 \times 10^{5}$ \\
& 37534.9 & 3151 & 710.5 & $2.383 \times 10^{6}$ \\
& 36618.8 & 15229 & 1256.6 & $2.037 \times 10^{7}$ \\
& 35728.9 & 1924 & 2455.8 & $5.020 \times 10^{6}$ \\
$\mathrm{Kr}$ & 39486.9 & 6883 & 299.0 & $2.190 \times 10^{6}$ \\
& 39334.7 & 1249 & 371.7 & $4.944 \times 10^{6}$ \\
& 39149.0 & 5122 & 503.0 & $2.742 \times 10^{6}$ \\
& $38513.5^{\mathrm{a}}$ & 619 & 1650 & $1.050 \times 10^{6}$ \\
& 40038.0 & 5482 & 252.5 & $1.473 \times 10^{6}$ \\
$\mathrm{Ar}$ & 39899.3 & 9309 & 329.4 & $3.263 \times 10^{6}$ \\
& 39734.6 & 2967 & 467.2 & $1.475 \times 10^{6}$ \\
\hline \hline
\end{tabular}

a This broad feature originates from the remnants of a thermally unstable site that still existed in this annealed $\mathrm{Hg} / \mathrm{Kr}$ sample.

sion components as 37535,36619 , and $35729 \mathrm{~cm}^{-1}$. The excitation spectra recorded for all three components resulted in identical profiles indicating they are not due to site effects. These $\mathrm{Hg} / \mathrm{Xe}$ samples were deposited at $35 \mathrm{~K}$ to minimize the formation of multiple trapping sites, hence we conclude the three components in the ${ }^{3} P_{1}$ state emission centered at $273 \mathrm{~nm}$ arise from the occupancy of $\mathrm{Hg}$ in a single site in xenon.

The $42 \mathrm{~K}$ spectrum, shown on the right-hand side of Fig. 3, could also be fit adequately with three bands. An indication of the quality of the fits is provided in the upper panels which show the residuals existing between data and fit. Also shown are the emission profiles generated in the fit. The comparison of the low and high temperature fits, shown on the bottom of Fig. 3, suggests that the origin of the unexpected blueshift occurring at higher temperatures in the emission band, arises from the increasing intensity of the unresolved blue component. However, when the spectra are plotted on absolute intensity, it becomes clear that it is the intensity of the central component which is decreasing at higher temperatures.

Line shape analyses of the emission bands in the $\mathrm{Hg} / \mathrm{Ar}$ and $\mathrm{Hg} / \mathrm{Kr}$ systems were also conducted, the results of which are shown in Fig. 4 and collected in Table II. As in the Hg/Xe system, allowance had to be made in the $\mathrm{Hg} / \mathrm{Kr}$ system for the presence of a weak ${ }^{3} P_{0}$ state emission. This component and a broad underlying feature, due to a thermally unstable site, occur to the red of the main ${ }^{3} P_{1}$ state emission in $\mathrm{Kr}$. Adequate fits in $\mathrm{Hg} / \mathrm{Ar}$ were only obtained when three components were allowed for, as shown on the left-hand side of Fig. 4. The temperature dependence in the $\mathrm{Hg} / \mathrm{Ar}$ and $\mathrm{Hg} / \mathrm{Kr}$ systems is simpler than in the $\mathrm{Hg} / \mathrm{Xe}$ system in so far as the emission bands broaden and redshift with increasing temperature.

\section{B. $\mathrm{Hg}^{3} P_{0} \rightarrow{ }^{1} S_{0}$ emission spectra}

In this section, details of the $\mathrm{Hg}{ }^{3} P_{0}$ state emission spectra resulting from intermultiplet relaxation following pulsed laser excitation of the ${ }^{3} P_{1}$ level are presented. The combination of a high intensity, low repetition light source (Nd:YAG
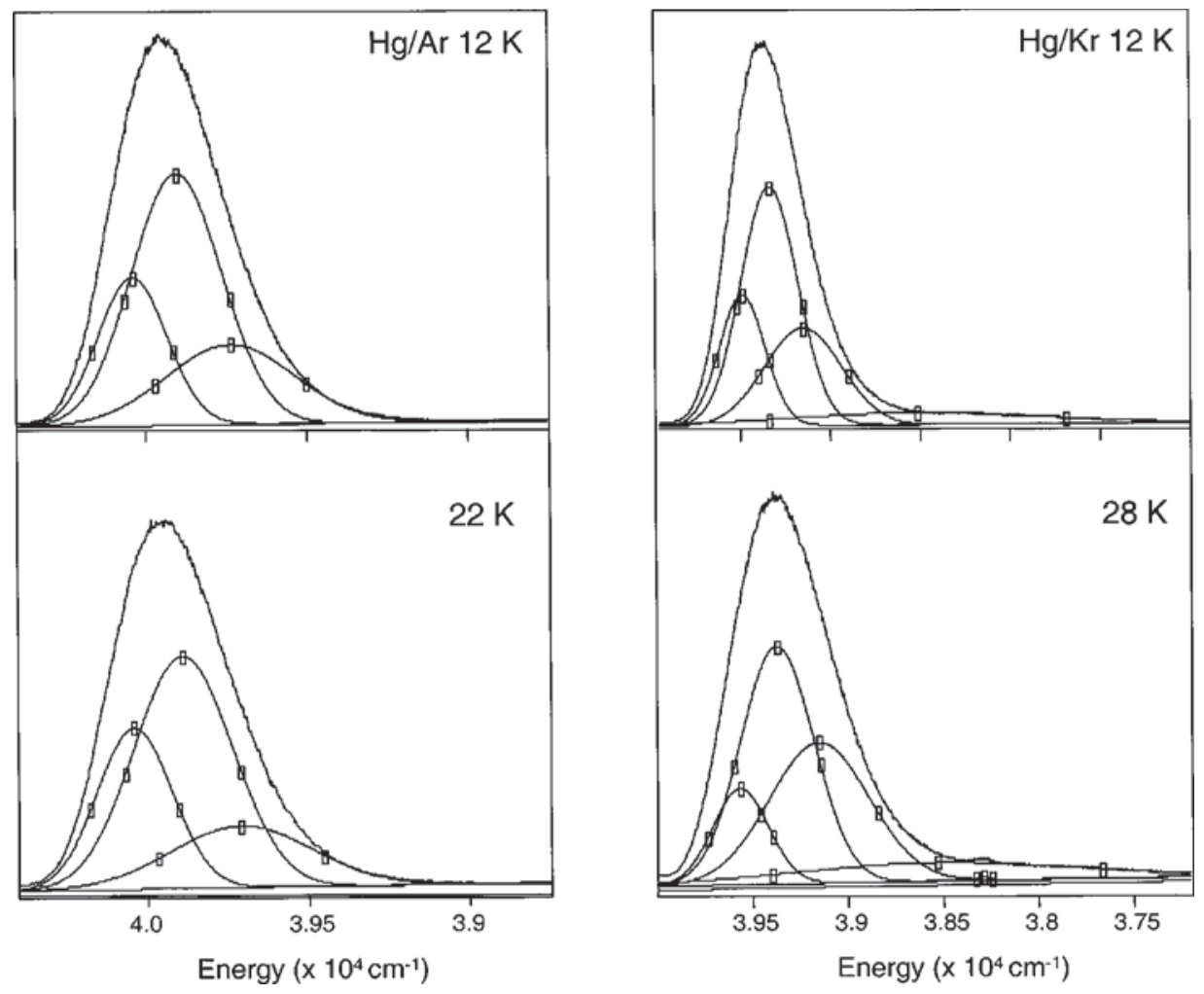

FIG. 4. Line shape analyses of ${ }^{3} P_{1}$ state emission in the $\mathrm{Hg} / \mathrm{Ar}$ and $\mathrm{Hg} / \mathrm{Kr}$ systems. The panels on the top show acceptable fits of spectra recorded at $12 \mathrm{~K}$, revealing the presence of multiple components in the $\mathrm{Ar}$ and $\mathrm{Kr}$ systems as observed in $\mathrm{Hg} / \mathrm{Xe}$. In contrast to the $\mathrm{Hg} / \mathrm{Xe}$ system, little temperature dependence is exhibited as indicated in the panels on the bottom. The fourth Gaussian component used in the $\mathrm{Hg} / \mathrm{Kr}$ system was required to account for a small amount of a red site present in this sample. Numerical values extracted in these fits are collected in Table II. 


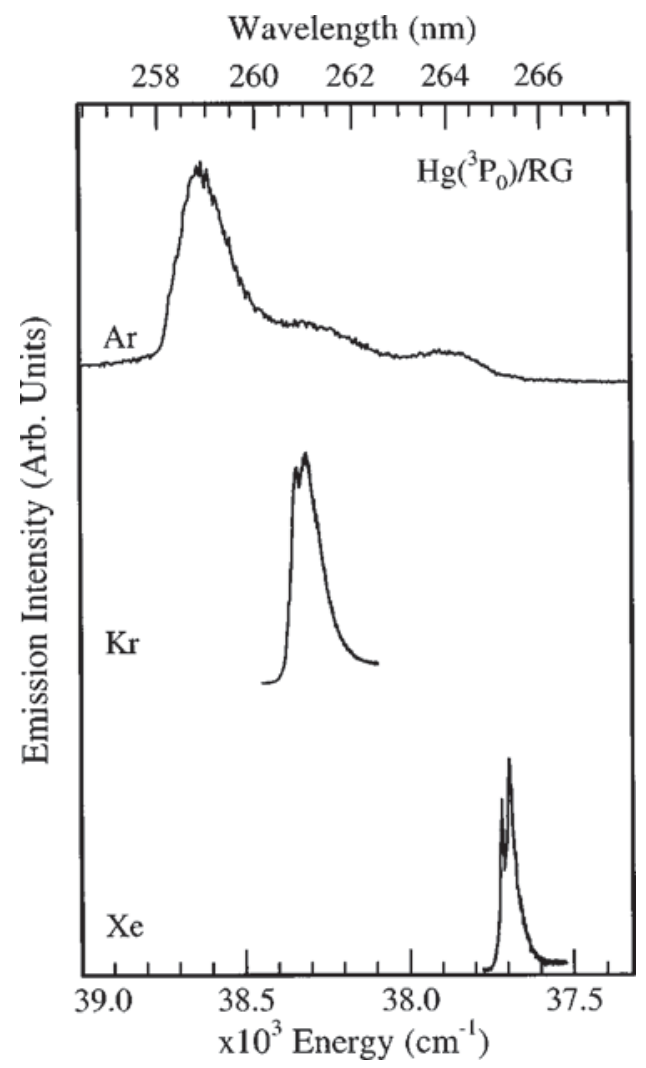

FIG. 5. A summary of the long-lived emission features recorded in the $\mathrm{Hg} / \mathrm{RG}$ systems at $12 \mathrm{~K}$. These emission spectra were produced with pulsed laser excitation of the $\mathrm{Hg}$ atom ${ }^{3} P_{1} \leftarrow{ }^{1} S_{0}$ transition and are gated to show only long-lived ${ }^{3} P_{0}$ emission. Note the increasing redshift in the emission bands on going from Ar to Xe but the decreasing linewidth.

laser) with photon counting detection is used as it favors the long-lived ${ }^{3} P_{0}$ emission over the nanosecond ${ }^{3} P_{1}$ fluorescence. Hence these spectra are free of the ${ }^{3} P_{1}$ state emission bands described in the preceding section.
The excitation wavelengths chosen correspond to the $\mathrm{Hg}$ ${ }^{3} P_{1} \leftarrow{ }^{1} S_{0}$ transition in solid Ar, Kr, and Xe, at 245.9, 248.8, and $253 \mathrm{~nm}$, respectively. As shown in Fig. 5, the emission features resulting from pulsed laser excitation are centered at 258.9, 260.8, and $265.1 \mathrm{~nm}$ in Ar, Kr, and Xe. The spectra shown in Fig. 5 exhibit a progressive redshift and decreasing linewidth from Ar to Xe. The redshift mirrors that of the ${ }^{3} P_{1}$ emission but the linewidth behavior is the reverse of that shown in Fig. 1 for the ${ }^{3} P_{1}$ fluorescence. It should be noted that the progressive redshift evident in Fig. 5 was not present in CT's data. ${ }^{7}$ In their spectra, the position of the $\mathrm{Hg} / \mathrm{Ar}$ emission was intermediate between that of $\mathrm{Kr}$ and $\mathrm{Xe}$. It is thought that the ${ }^{3} \mathrm{P}_{0}$ data presented in the earlier $\mathrm{Hg} / \mathrm{Ar}$ work, corresponds to $\mathrm{Hg}$ occupancy in a secondary site ${ }^{13}$ of argon.

The emission features in $\mathrm{Kr}$ and Xe matrices reveal finestructure splitting when recorded under high resolution. Thus as shown in Fig. 6, $\mathrm{Hg} / \mathrm{Xe}$ exhibits a narrow line (fwhm $\left.=10.5 \mathrm{~cm}^{-1}, \quad \nu_{0}=37718.4 \mathrm{~cm}^{-1}\right)$ at $265.122 \mathrm{~nm}$ and a broader red feature $\left(\mathrm{fwhm}=70 \mathrm{~cm}^{-1}, \nu_{0}=37658.4 \mathrm{~cm}^{-1}\right.$ ) at $265.545 \mathrm{~nm}$. High temperature scans, also shown in Fig. 6, indicate that the sharp feature is reversibly removed while the broad feature broadens and redshifts. These line shapes and their temperature dependence are characteristic of a zero phonon line (ZPL), for the narrow blue feature and a phonon sideband for the broader, red feature. Two features are evident in the $\mathrm{Hg} / \mathrm{Kr}$ system although not as well resolved as in $\mathrm{Hg} / \mathrm{Xe}$, but exhibiting the same temperature dependence. The main band of $\mathrm{Hg} / \mathrm{Ar}$ at $258.9 \mathrm{~nm}$ exhibits little temperature dependence, except that the pair of weak sidebands are removed at high temperature.

To investigate the origin of the splitting observed at high resolution for the ${ }^{3} P_{0}$ state emission in $\mathrm{Hg} / \mathrm{Xe}$, a line shape analysis was conducted using the $W p$ optical function. This function was given originally by Huang and Rhys ${ }^{15}$ and is

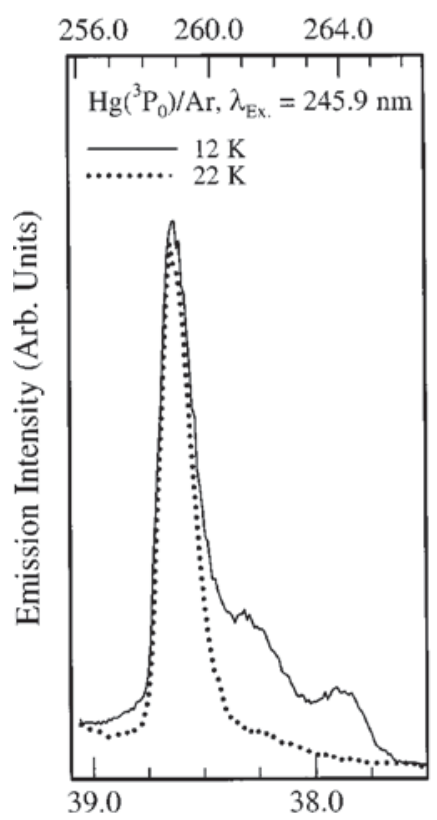

Wavelength (nm)

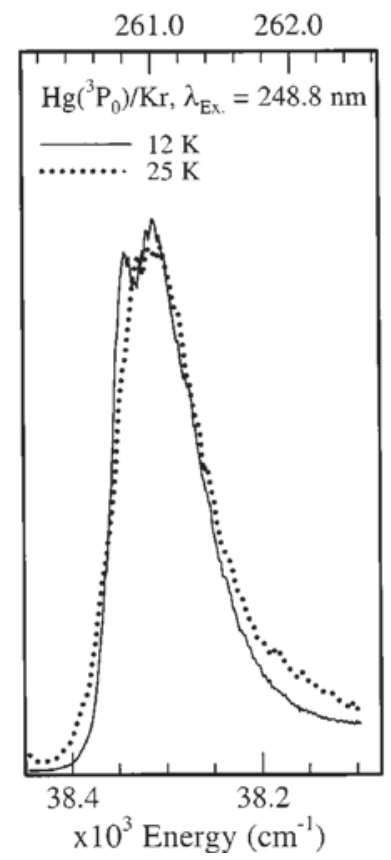

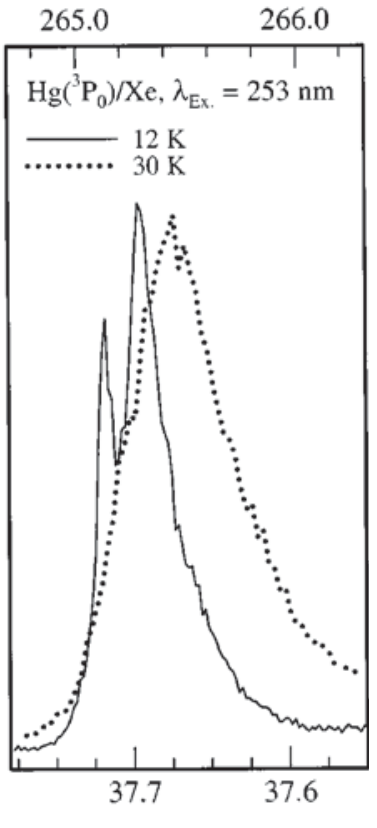

FIG. 6. High resolution scans of the $\mathrm{Hg}{ }^{3} \mathrm{P}_{0}$ state emission in $\mathrm{Ar}, \mathrm{Kr}$, and Xe yielding resolved fine structure in the $\mathrm{Hg} / \mathrm{Kr}$ and $\mathrm{Hg} / \mathrm{Xe}$ systems. The solid traces were recorded at $12 \mathrm{~K}$. High temperatures scans are shown by the dotted lines indicating reversible changes in the $\mathrm{Hg} / \mathrm{Kr}$ and $\mathrm{Hg} / \mathrm{Xe}$ spectra. The main band in the Hg/Ar system exhibits little temperature dependence but the weak pair of red bands, assigned to defect site occupancy, are quenched at elevated temperatures. 


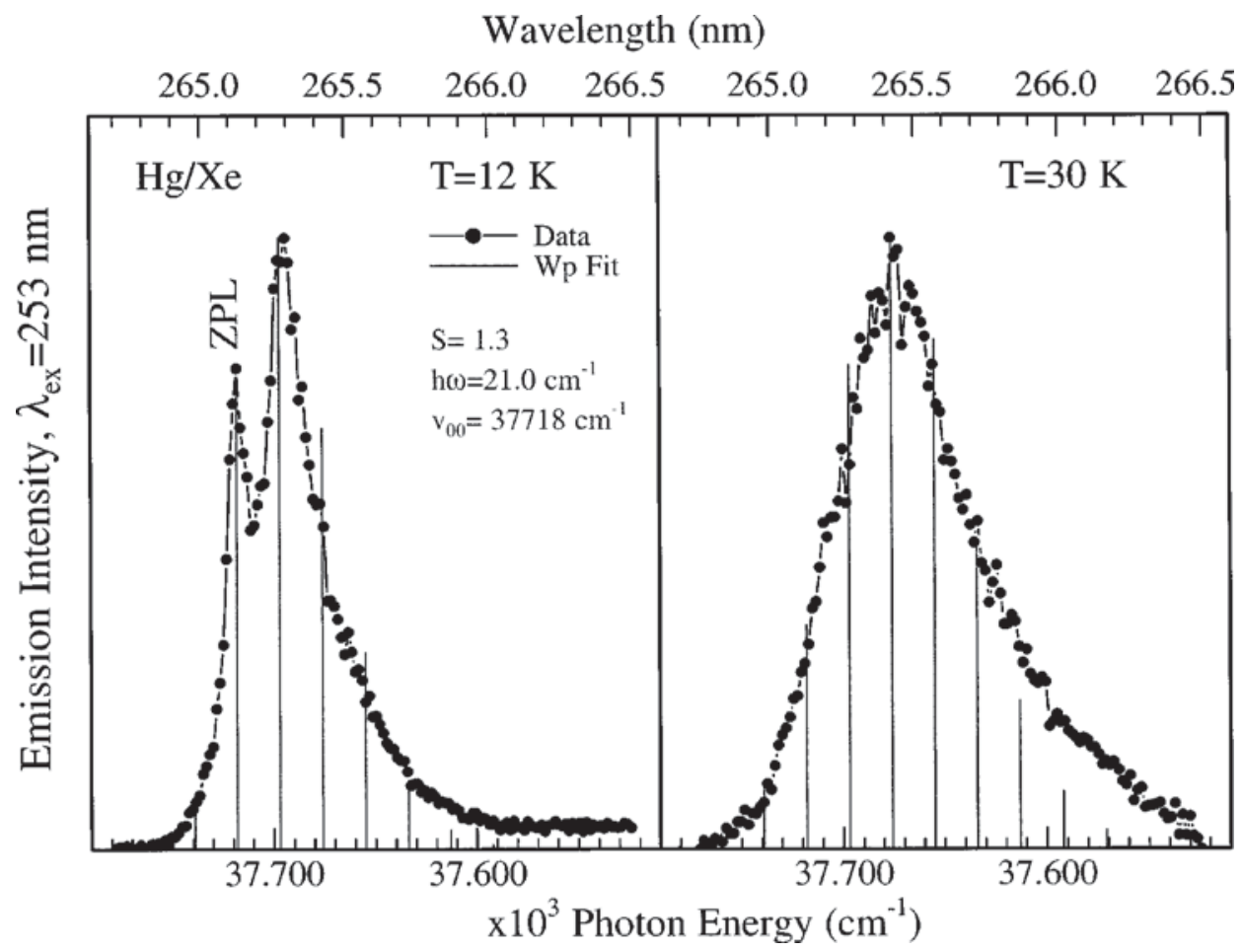

FIG. 7. The $W p$ line shapes calculated with Eq. (1) for the ${ }^{3} P_{0}$ state emission in $\mathrm{Hg} / \mathrm{Xe}$ recorded at 12 and $30 \mathrm{~K}$ and produced with pulsed laser excitation at $253 \mathrm{~nm}$. The location of the zerophonon line in the spectrum is indicated as ZPL and numerically as $\nu_{0,0}$. The presence of hot emission in the 12 $\mathrm{K}$ spectrum is made evident in the comparison of fit and data, which reveals the existence of a line to the blue of the ZPL.

described in detail by Struck and Fonger ${ }^{16}$ as

$$
W p=\exp \left(-S \frac{1+r}{1-r}\right) r^{-p / 2} I p\left(2 S \frac{r^{1 / 2}}{1-r}\right) \text {. }
$$

In this expression $r=\exp (-\hbar \omega / k T)$ and $I p(x)$ is a modified Bessel function of variable order $p$ and at a given temperature $T$, of fixed argument $\theta=2 S r^{1 / 2} /(1-r)$. The function $(W)$ provides the distribution of intensity as a function of phonon number $(p)$. It essentially provides Franck-Condon intensity factors for a single phonon mode of frequency $\hbar \omega$, coupling to the electronic transition with a strength $S$, a term known as the Huang-Rhys factor. For large $S$, the $W p$ function approaches a Gaussian function. To maintain numerical accuracy in the weak electron-phonon characteristics of the $\mathrm{Hg}{ }^{3} P_{0}$ state emission spectra, the sum form of the $W p$ function was used in our programming. The sum form is

$W p=\exp \left(-S \frac{1+r}{1-r}\right)\left(\frac{\theta}{2}\right)^{p} \sum_{k=0}^{\theta m}\left(\frac{\theta^{2}}{4}\right)^{k} /[k ! \Gamma(p+k+1)]$

and its evaluation is truncated at $\theta_{m}$, the next integer greater than $\theta+1$. Clearly, the sum increases with the electronphonon coupling strength $S$ and the temperature.

The fit allows identification of the position of the zerophonon line (ZPL or $\nu_{0,0}$ ), and the magnitude of the strength electron-phonon coupling $S$ once the recorded spectrum has been transformed into phonon units $p$. This initially involves estimating the magnitude of the phonon frequency $\hbar \omega$, a task which was direct in the $12 \mathrm{~K} \mathrm{Hg} / \mathrm{Xe}$ spectrum due to the ZPL being resolved. A satisfactory fit, obtained with $S=1.3$ and $\hbar \omega=21.0 \mathrm{~cm}^{-1}$, is shown on the left-hand side of Fig. 7 . The fit verifies the ZPL is located at $37718 \mathrm{~cm}^{-1}$, the phonon sideband is as expected to the red of this, but it also reveals the presence of weak hot emission at $37739 \mathrm{~cm}^{-1}$ to the blue of the ZPL. Using the $12 \mathrm{~K}$ fit parameters $(S, \hbar \omega$, and $\nu_{0,0}$ ) the line shape calculated with $T=30 \mathrm{~K}$ is compared on the right-hand side of Fig. 7 with the emission spectrum recorded at this temperature. Evident in this plot is the diminished intensity of the ZPL and the gain in the intensity of the phonon sideband now showing a maximum at $37673 \mathrm{~cm}^{-1}$.

Similar fits were performed on the ${ }^{3} P_{0}$ emission in $\mathrm{Hg} / \mathrm{Kr}$ and $\mathrm{Hg} / \mathrm{Ar}$, the results of which are collected in Table III. A satisfactory fit was obtained in $\mathrm{Hg} / \mathrm{Kr}$ with $S=2.2$, $\hbar \omega=28.0 \mathrm{~cm}^{-1}$ and $\nu_{0,0}=38366 \mathrm{~cm}^{-1}$. The comparison shown on the right-hand side of Fig. 8 indicates that the ZPL is not resolved in $\mathrm{Hg} / \mathrm{Kr}$ but is located as a blue shoulder on the partially resolved feature. The fits conducted in $\mathrm{Hg} / \mathrm{Ar}$ are not as definitive as those in $\mathrm{Hg} / \mathrm{Xe}$ or $\mathrm{Hg} / \mathrm{Kr}$ because fine-structure splitting has not been resolved to provide an initial estimate of the phonon frequency, $\hbar \omega$. However, the line shape generated with $S=3.3, \hbar \omega=41.0 \mathrm{~cm}^{-1}$ and $\nu_{0,0}$ $=38740 \mathrm{~cm}^{-1}$ compares well, as shown on the left-hand side of Fig. 8 with the observed emission band. This fit indicates the ZPL is too weak to be resolved in the emission spectrum.

The two weak features in the $\operatorname{Hg}\left({ }^{3} P_{0}\right) / \mathrm{Ar}$ emission spectrum at 261.17 and $263.75 \mathrm{~nm}$ (see Figs. 5 and 6), have always been present in the samples we have prepared. As shown in Fig. 6, both of these low energy features are absent in the high temperature scans but reappear at $12 \mathrm{~K}$. It has also been observed that the intensities of these two features are increased dramatically by the introduction of a third species to the $\mathrm{Hg} / \mathrm{Ar}$ matrix. This is most evident in Ar samples containing less than $0.1 \% \mathrm{Xe}$, where the intensities of the red pair increase together relative to the $258.9 \mathrm{~nm}$ band. Crepin et al. previously ${ }^{7}$ assigned the $263.75 \mathrm{~nm}$ feature to an $\mathrm{Hg}: \mathrm{H}_{2} \mathrm{O}$ complex in the Ar matrix, however, we find this band accompanies the $261.17 \mathrm{~nm}$ feature and both are 


\section{Wavelength $(\mathrm{nm})$}

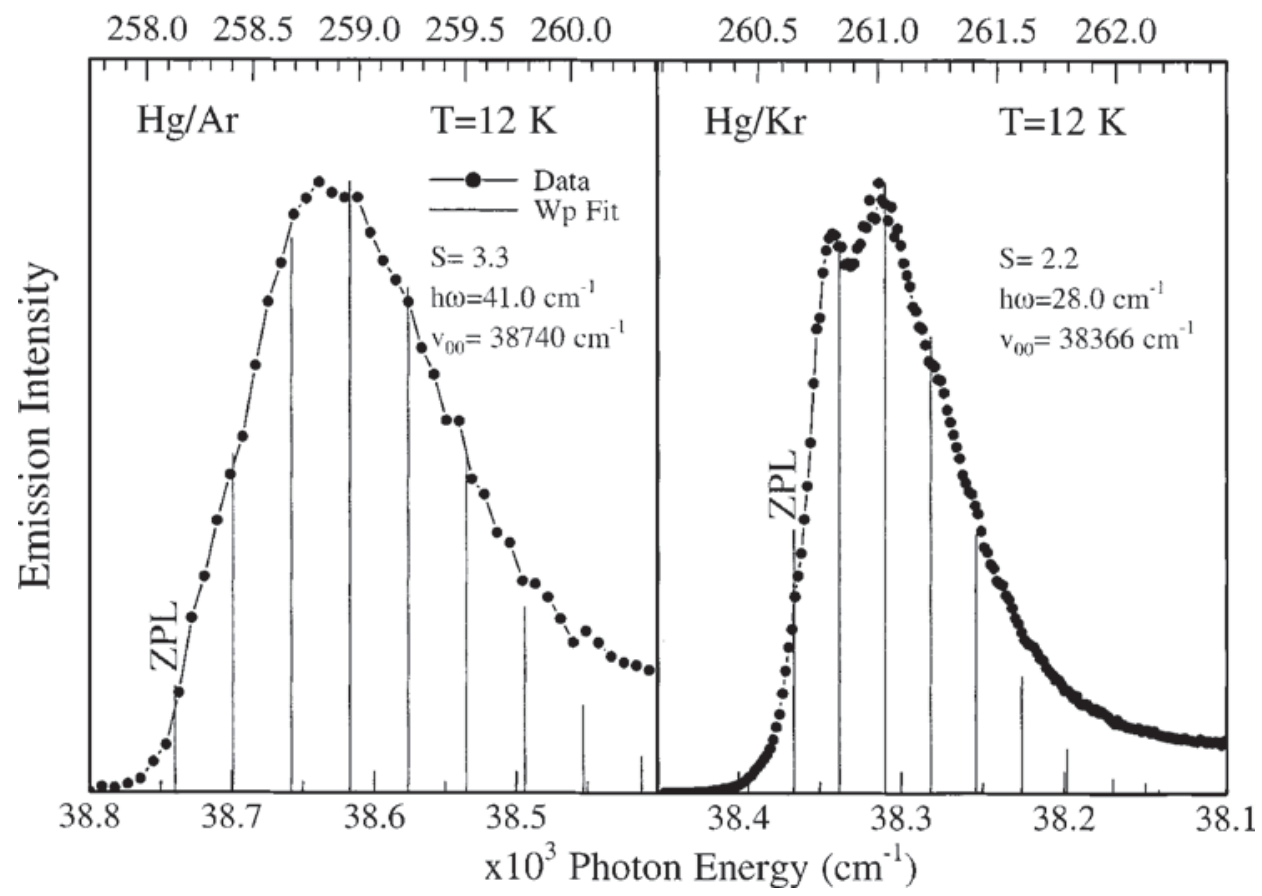

FIG. 8. The $W p$ line shapes calculated for the ${ }^{3} P_{0}$ state emission in the $\mathrm{Hg} / \mathrm{Ar}$ and $\mathrm{Hg} / \mathrm{Kr}$ systems. The $\mathrm{Hg} / \mathrm{Ar}$ emission was produced with laser excitation at $245.9 \mathrm{~nm}$, the $\mathrm{Hg} / \mathrm{Kr}$ spectrum with $248.8 \mathrm{~nm}$ excitation. present in Ar samples free of water. Thus, we assign this pair to mercury atom occupancy in imperfect sites in the Ar lattice, for example, a substitutional site with one of the 12 nearest neighbor atoms missing.

Long decay times, ranging from 8-530 ms, were recorded for the emission bands of $\mathrm{Ar}, \mathrm{Kr}$, and Xe shown in Figs. 5 and 6, verifying that they correspond to the strongly forbidden $\mathrm{Hg}{ }^{3} P_{0} \rightarrow{ }^{1} S_{0}$ transition. Least squares fits with a triple-exponential function were required to obtain adequate fits. This is indicative of complex decay kinetics, behavior already reported ${ }^{7}$ by Crepin et al. It should be noted however that by far the largest component in the decay curve has the shortest decay time ( $\tau=8.8 \mathrm{~ms}$ ) while the longest decay ( $\tau$ $=541 \mathrm{~ms}$ ) is found only on the red emission band and is the weakest component.

\section{DISCUSSION}

\section{A. $\mathrm{Hg}^{3} P_{1} \rightarrow{ }^{1} S_{0}$ emission}

The gross spectral features recorded for the $\mathrm{Hg}{ }^{3} P_{1}$ $\rightarrow{ }^{1} S_{0}$ transition in this study are in very good agreement with the earlier work of Crepin and Tramer. ${ }^{7}$ High resolution scans of the emission bands reveal complex profiles, requiring multiple emission components to yield adequate line shape fits. Of the Hg/RG systems, the most complex behavior is exhibited by the emission in $\mathrm{Hg} / \mathrm{Xe}$, which shows a blueshift with increasing temperature. Calculation of the $W p$ optical function for the ${ }^{3} P_{1}$ state emission in xenon yields a Gaussian curve with an electron-phonon coupling strength $S$ of 105 . This is almost two orders of magnitude greater than the value of 1.3 for the ${ }^{3} P_{0}$ state emission and closely replicates the central Gaussian in the line shape analysis of the $273 \mathrm{~nm}$ band. Gaussian fits done as a function of temperature reveal that the intensity of the central component is diminishing at high temperature. The origin of the multiple emis- sion components in the Hg/RG systems is known from excitation scans not to be due to multiple site occupancy. Pairpotential simulations described in the following paper, ${ }^{6}$ present a model which explains the origin of multiple emission features for atomic mercury isolated at a single site. These calculations also suggest a mechanism for the quenching of the central emission component in the $273 \mathrm{~nm}$ emission in the $\mathrm{Hg} / \mathrm{Xe}$ system.

\section{B. $\mathrm{Hg}^{3} \boldsymbol{P}_{0} \rightarrow{ }^{1} S_{0}$ emission}

The spectral and temporal characteristics of the $\mathrm{Hg}$ atom ${ }^{3} P_{1}$ and ${ }^{3} P_{0}$ excited state emissions are very different making them, as the comparison presented in Fig. 2 for $\mathrm{Hg} / \mathrm{Xe}$ illustrates, easy to differentiate. Although the ${ }^{3} P_{0}$ state was easily observed with laser excitation in the three rare gas hosts used, the actual amount of it produced with ${ }^{3} P_{1}$ state excitation is rather small relative to emission of the ${ }^{3} P_{1}$ state. The inefficiency of the ${ }^{3} P_{1} \rightarrow{ }^{3} P_{0}$ intramultiplet relaxation is made clear in Fig. 1, where the only $\mathrm{Hg} / \mathrm{RG}$ system showing a clear sign of the ${ }^{3} P_{0}$ state in continuous (timeintegrated) emission is $\mathrm{Hg} / \mathrm{Xe}$. Even in $\mathrm{Hg} / \mathrm{Xe}$, the ratio of the radiative to the intramultiplet relaxation processes is estimated as 200:1 from the line shape analysis presented in Fig. 3 and the corresponding numerical data collected in Table II. Moreover, the efficiency of the intramultiplet relaxation is not enhanced with increasing temperature up to $42 \mathrm{~K}$ as shown in Fig. 3.

Optical line shapes generated with the $W p$ function indicate the ${ }^{3} P_{0}$ emission in the solid rare gases involves weak electron-phonon coupling. The $S$ values extracted are 1.3, 2.2, and 3.3 for $\mathrm{Xe}, \mathrm{Kr}$, and Ar, respectively. In solid state spectroscopy, weak electron-phonon coupling is indicative of unshifted potentials for the two states involved in the optical transition. While the ground and many of the excited 
TABLE III. The location of the ZPL extracted in the $W p$ line shape function analysis conducted on the recorded atomic $\mathrm{Hg}{ }^{3} P_{0} \leftrightarrow{ }^{1} S_{0}$ emission in solid $\mathrm{Ar}, \mathrm{Kr}$, and Xe. For comparison purposes, the results of a similar analysis on the central component in the $\mathrm{Hg} / \mathrm{Xe}^{3} P_{1} \leftrightarrow{ }^{1} S_{0}$ emission are also given.

\begin{tabular}{llccc}
\hline \hline $\mathrm{Hg} / \mathrm{RG}$ & Transition & $\begin{array}{c}\mathrm{ZPL} \\
\nu_{0,0}\left(\mathrm{~cm}^{-1}\right)\end{array}$ & \multicolumn{1}{c}{$S$} & $\hbar \omega\left(\mathrm{cm}^{-1}\right)$ \\
\hline $\mathrm{Hg} / \mathrm{Ar}$ & ${ }^{3} P_{0} \leftrightarrow{ }^{1} S_{0}$ & 38740 & 3.3 & 41 \\
$\mathrm{Hg} / \mathrm{Kr}$ & ${ }^{3} P_{0} \leftrightarrow{ }^{1} S_{0}$ & 38366 & 2.2 & 28 \\
$\mathrm{Hg} / \mathrm{Xe}$ & ${ }^{3} P_{0} \leftrightarrow{ }^{1} S_{0}$ & 37718 & 1.3 & 21 \\
$\mathrm{Hg} / \mathrm{Xe}$ & ${ }^{3} P_{1} \leftrightarrow{ }^{1} S_{0}$ & $\sim 39000$ & 105 & 21 \\
\hline \hline
\end{tabular}

state potentials of the $\mathrm{Hg} \cdot \mathrm{RG}$ complexes are accurately known, the $\widetilde{a}^{3} 0\left({ }^{3} \Sigma\right)$ states of the $\mathrm{Hg}\left({ }^{3} P_{0}\right) \cdot \mathrm{RG}$ diatomics cannot be determined directly be spectroscopic means. However, in the limit of Hund's case- $c$ coupling, it can be extracted from the $A^{3} 1\left({ }^{3} \Pi\right)$ and $B^{3} 0\left({ }^{3} \Sigma\right)$ states ${ }^{17,18}$ of the $\mathrm{Hg}\left({ }^{3} P_{1}\right) \cdot \mathrm{RG}$ diatomics with the equation

$$
V\left({ }^{3} P_{0}\right) \widetilde{a}^{3} 0=1 / 3\left[\left(V_{\Sigma}^{e}+V_{\Pi}^{e}\right)+V_{\Pi}\right]
$$

presented by Duval et al. ${ }^{19}$ In this expression $V_{\Pi}$ is the spectroscopic $A$ state, while $V_{\Sigma}$ is determined from the $A$ and $B$ states from the relationship $V_{\Sigma}=2 V_{B}-V_{A}$.

The potential energy curves extracted for the $\widetilde{a}^{3} 0\left({ }^{3} \Sigma\right)$ states of the $\operatorname{Hg}\left({ }^{3} P_{0}\right) \cdot R G$ diatomics from the spectroscopic $A$ and $B$ states are shown in Fig. 9 and their key parameters are collected in Table IV. It is evident on inspection of the curves shown in this plot that the ground $\operatorname{Hg}\left({ }^{1} S_{0}\right)$ - RG/X ${ }^{1} 0\left({ }^{1} \Sigma\right)$ and excited $\mathrm{Hg}\left({ }^{3} P_{0}\right) \cdot \mathrm{RG} / \widetilde{a}^{3} 0\left({ }^{3} \Sigma\right)$ state potential energy curves are very similar. Conversely the form of the excited $\mathrm{Hg}\left({ }^{3} P_{1}\right) \cdot \mathrm{RG} / A^{3} 1\left({ }^{3} \Pi\right)$ state potentials are very different to the ground states. This explains the very strong electron-phonon exhibited on the $\operatorname{Hg}\left({ }^{3} P_{1}\right)$ state emissions (e.g., $\mathrm{Hg} / \mathrm{Xe}, S=105$ ) and the very weak coupling on the $\operatorname{Hg}\left({ }^{3} P_{0}\right)$ state emission $(S=1.3)$.

Closer scrutiny of the bond lengths collected in Table IV, reveals that another parameter plays a role in determining the electron-phonon coupling strengths. Specifically, the
TABLE IV. Comparison of the key molecular parameters of the ground $X^{1} 0^{+}\left({ }^{1} \Sigma\right)$ and excited $\widetilde{a}^{3} 0^{-}\left({ }^{3} \Sigma\right)$ states of the $\mathrm{Hg} \cdot \mathrm{RG}$ diatomics. The $\widetilde{a}\left({ }^{3} 0^{-}\right)$state was obtained from Eq. (3) using the spectroscopic potentials presented in Ref. 17 for the $\operatorname{Hg}\left({ }^{3} P_{1}\right) \cdot \operatorname{RG}\left[A^{3} \Pi\left({ }^{3} 0^{+}\right)\right]$and $\left[B^{3} \Sigma\left({ }^{3} 1\right)\right]$ states. Also shown are the bond lengths of the rare gas dimers.

\begin{tabular}{ccccc}
\hline \hline State & Parameter & $\mathrm{Hg} \cdot \mathrm{Ar}$ & $\mathrm{Hg} \cdot \mathrm{Kr}$ & $\mathrm{Hg} \cdot \mathrm{Xe}$ \\
\hline$\widetilde{a}^{3} 0^{-}\left({ }^{3} \Sigma\right)$ & $D_{e}\left(\mathrm{~cm}^{-1}\right)$ & 92 & 136 & 351 \\
& $R_{e}(\AA)$ & 4.26 & 4.13 & 3.6 \\
$X^{1} 0^{+}\left({ }^{1} \Sigma\right)$ & $D_{e}\left(\mathrm{~cm}^{-1}\right)$ & 130.25 & 178 & 254 \\
& $R_{e}(\AA)$ & 3.98 & 4.07 & 4.25 \\
$X \mathrm{RG} \cdot \mathrm{RG}$ & $D_{e}\left(\mathrm{~cm}^{-1}\right)$ & 99.5 & 138.4 & 196 \\
& $R_{e}(\AA)$ & 3.756 & 4.017 & 4.363 \\
\hline \hline
\end{tabular}

$\widetilde{a}^{3} 0\left({ }^{3} \Sigma\right)$ and $X^{1} 0\left({ }^{1} \Sigma\right)$ state bond lengths are almost identical in the $\mathrm{Hg} \cdot \mathrm{Kr}$ case and differ by larger amounts in the $\mathrm{Hg} \cdot \mathrm{Ar}$ and $\mathrm{Hg} \cdot \mathrm{Xe}$ cases. It will be remembered that the weakest electron-phonon coupling strength was identified in Xe, not in Kr. Application of Eq. (3), in the extraction of the $\widetilde{a}^{3} 0\left({ }^{3} \Sigma\right)$ states, assumes case (c) coupling but as this is expected to be reasonable in the case of the $\mathrm{Hg} \cdot \mathrm{RG}$ diatomics, some other factor must be partly determining the $S$ value. Another parameter that plays a role in this regard is the site size presented by the solid. From the comparison made in Table IV of the substitutional site sizes of the solid rare gases with the $\mathrm{Hg}$ - RG ground state bond lengths, it is clear that Xe is the only system where the site size of the solid is larger than the bond length of any $\mathrm{Hg}$. Xe state. Thus, in the case of $\mathrm{Hg} \cdot \mathrm{Xe}$, emission will terminate in a state whose bond length is less than the Xe-Xe distances in the lattice. Hence, little or no coupling will occur between the optically active $\mathrm{Hg}$ - $(\mathrm{Xe})_{n}$ quasimolecule and the delocalized phonons of solid xenon. On this basis, stronger (but still weak) coupling is anticipated in $\mathrm{Kr}$ where the $\mathrm{Hg} \cdot \mathrm{Kr}$ ground state bond length (4.07 $\AA$ ) only slightly exceeds that of $\mathrm{Kr}-\mathrm{Kr}(4.017 \AA)$. In solid Ar, the nearest neighbor distance (3.756 $\AA$ ) is considerably shorter than the ground state bond length (3.98 $\AA$ ) of $\mathrm{Hg} \cdot \mathrm{Ar}$. In this case, emission will return a ground state con-
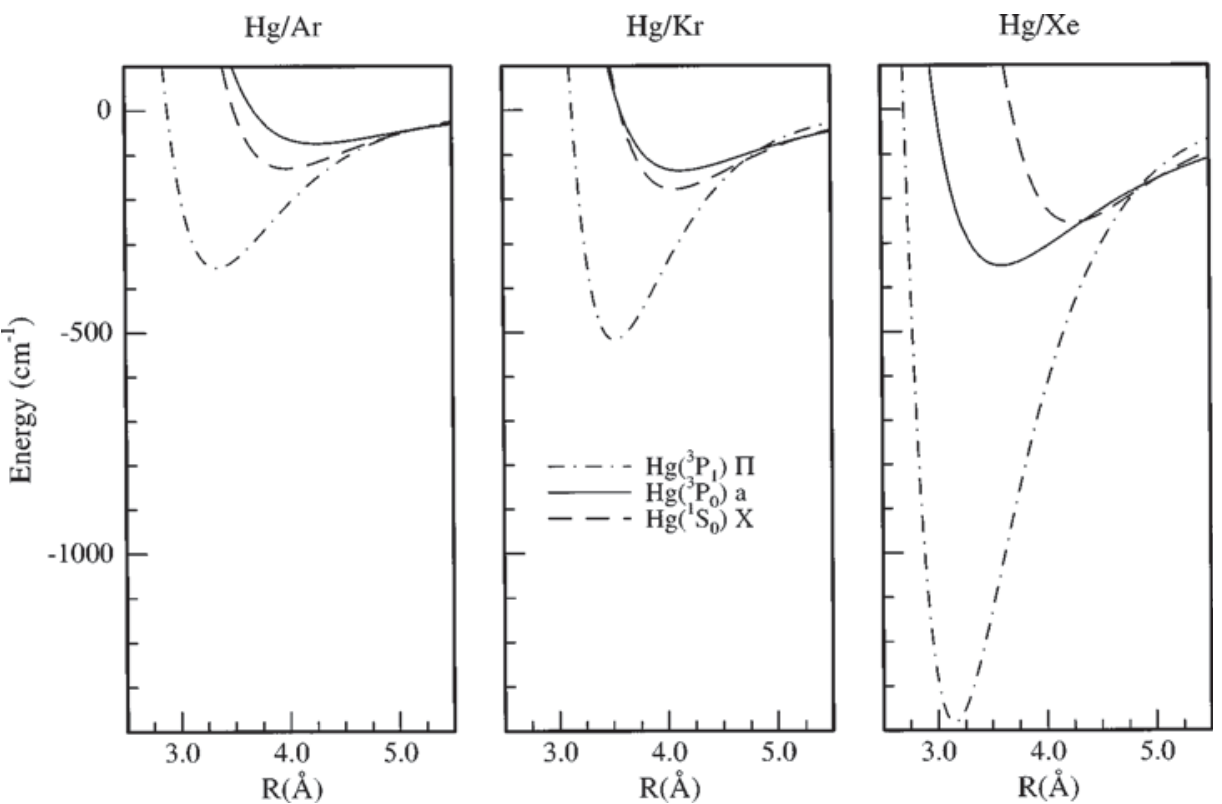

FIG. 9. Potentials of the Hg. RG diatomics of relevance to the $\mathrm{Hg}\left({ }^{3} P_{0}\right) / \mathrm{RG}$ matrix emission spectra. The $X$ and the $A(\Pi)$ state potentials are obtained directly from spectroscopic data of the $\mathrm{Hg} \cdot \mathrm{RG}$ diatomics given in Ref. 19 while the $\widetilde{a}^{3} 0^{-}$state potential was obtained with Eq. (3) which assumes case (c) coupling. Noteworthy is the similarity of the $\widetilde{a}^{3} 0^{-}$state and $X$ state potentials and the dissimilarity of the $A(\Pi)$ and $X$ states. 
figuration almost $0.25 \AA$ more extended than the equilibrium Ar lattice positions. This will necessarily result in stronger coupling with the lattice phonons.

\section{CONCLUSIONS}

The sharp, weak feature centered at $37693.9 \mathrm{~cm}^{-1}$ in $\mathrm{Hg} / \mathrm{Xe}$ is the $6 p^{3} P_{0} \rightarrow 6 s{ }^{1} S_{0}$ transition and arises from of intramultiplet ${ }^{3} P_{1} \rightarrow{ }^{3} P_{0}$ relaxation. The contribution of this band to the time integrated emission intensity is only $0.5 \%$ indicating the inefficiency of intramultiplet ${ }^{3} P_{1} \rightarrow{ }^{3} P_{0}$ relaxation compared with radiative decay of the ${ }^{3} P_{1}$ excited state. The efficiency of the intramultiplet relaxation increases, but only very slightly, at higher temperatures. The presence of resolved fine structure on the $\mathrm{Hg}{ }^{3} \mathrm{P}_{0} \rightarrow{ }^{1} S_{0}$ emission bands in $\mathrm{Xe}$ (and partly in $\mathrm{Kr}$ ) matrices and the temperature dependence exhibited, suggested assignment of a resolved zero phonon line and a phonon side band. This assignment is confirmed in the line shape simulation conducted with the $W p$ function yielding small $S$ values (1.3 and 2.2 in Xe and $\mathrm{Kr}$, respectively) which represent weak electron-phonon coupling. The close match between the excited $\mathrm{Hg}$ - RG $\left({ }^{3} P_{0}\right) \widetilde{a}^{3} 0^{-}\left({ }^{3} \Sigma\right)$ and ground $X \mathrm{Hg} \cdot \mathrm{RG}\left({ }^{1} S_{0}\right){ }^{1} 0^{+}\left({ }^{1} \Sigma\right)$ state bond lengths is the origin of the very weak electron-phonon coupling in the $\operatorname{Hg}\left({ }^{3} P_{0}\right) / R G$ matrix system. Conversely the dissimilarity in the bond lengths in the excited $A \mathrm{Hg} \cdot \mathrm{RG}\left({ }^{3} P_{1}\right)^{3} 1\left({ }^{3} \Pi\right)$ state and ground $X \mathrm{Hg}$ - $\operatorname{RG}\left({ }^{1} S_{0}\right)^{1} 0^{+}\left({ }^{1} \Sigma\right)$ state potentials explains the large linewidths on the $\mathrm{Hg}\left({ }^{3} P_{1}\right) / \mathrm{RG}$ matrix bands. The multicomponent nature of the ${ }^{3} P_{1}$ state emission is shown not to arise from solid state effects such as multiple site trapping. Its origin is examined in the theoretical paper directly following ${ }^{6}$ where the energetics of excited state vibronic modes are calculated with pair-potential methods for $\mathrm{Hg}\left({ }^{3} P_{1}\right) / \mathrm{RG}_{18}$ clusters.

\section{ACKNOWLEDGMENTS}

This research was funded by the Irish Government Enterprise Ireland, SC/98/403 Basic Science research grant scheme to whom M.C. gratefully acknowledges receipt of a Ph.D. studentship.

${ }^{1}$ W. H. Breckenridge, C. Jouvet, and B. Soep, in Advances in Metal and Semiconductor Clusters, edited by M. Duncan (JAI, Greenwich, CT, 1995), Vol. 3.

${ }^{2}$ C. Crepin-Gilbert and A. Tramer, Int. Rev. Phys. Chem. 18, 485 (1999).

${ }^{3}$ M. McCarty and G. W. Robinson, Mol. Phys. 2, 415 (1959).

${ }^{4}$ J. G. McCaffrey and P. N. Kerins, J. Chem. Phys. 106, 7885 (1997).

${ }^{5}$ B. Healy and J. G. McCaffrey, J. Phys. Chem. A 104, 3553 (2000).

${ }^{6}$ M. A. Collier and J. G. McCaffrey, J. Chem. Phys. 119, 11888 (2003), following paper.

${ }^{7}$ C. Crepin and A. Tramer, J. Chem. Phys. 97, 4772 (1992).

${ }^{8}$ C. Crepin, F. Legay, N. Legay-Sommaire, and A. Tramer, Trends Chem. Phys. 7, 111 (1999).

${ }^{9}$ S. L. Laursen and H. E. Cartland, J. Chem. Phys. 95, 4751 (1991).

${ }^{10}$ M. Chergui, C. Crepin, T. Hebert, and A. Tramer, Chem. Phys. Lett. 197, 467 (1992).

${ }^{11}$ C. Crepin, M. Chergui, T. Hebert, L. Konig, P. Martin, and A. Tramer, J. Phys. Chem. 98, 3280 (1994).

${ }^{12}$ C. Crepin and A. Tramer, J. Chem. Phys. 100, 5467 (1994).

${ }^{13}$ C. Crepin and A. Tramer, J. Chem. Phys. 107, 2205 (1997).

${ }^{14}$ J. Helbing, A. Haydar, and M. Chergui, J. Chem. Phys. 113, 3621 (2000).

${ }^{15}$ K. Huang and A. Rhys, Proc. R. Soc. London, Ser. A 204, 406 (1950); reprinted in Selected Papers on Photoluminscence of Inorganic Solids, edited by M. J. Weber (SPIE-The International Society of Optical Engineering, Washington, D.C., 1998).

${ }^{16}$ C. W. Struck and W. H. Fonger, Understanding Luminscence Spectra and Efficiency Using Wp and Related Functions (Springer-Verlag, Berlin, 1991).

${ }^{17}$ J. Zuniga, A. Bastida, A. Requena, N. Halberstadt, and J. Beswick, J. Chem. Phys. 98, 1007 (1993).

${ }^{18}$ M. Okunishi, H. Nakazawa, K. Yamanouchi, and S. Tsuchiya, J. Chem. Phys. 93, 7526 (1990).

${ }^{19}$ M. C. Duval, O. B. D’Azy, W. H. Breckenridge, C. Jouvet, and B. Soep, J. Chem. Phys. 85, 6324 (1986). 